\title{
Correction to: Changes in nutritional status of children who lived in temporary shelters in Bhaktapur municipality after the 2015 Nepal earthquake
}

Bhim Gopal Dhoubhadel ${ }^{1,2^{*}+}$, Ganendra Bhakta Raya ${ }^{3 \dagger}$, Dhruba Shrestha ${ }^{3}$, Raj Kumar Shrestha ${ }^{3}$, Yogendra Dhungel ${ }^{3}$, Motoi Suzuki ${ }^{2}$, Michio Yasunami ${ }^{2,4}$, Chris Smith ${ }^{1}$, Koya Ariyoshi ${ }^{1,2,5}$ and Christopher M. Parry ${ }^{1,6,7}$

\section{Correction to: Trop Med Health 48, 53 (2020) https://doi.org/10.1186/s41182-020-00225-8}

Following publication of the original article [1], the authors would like to add affiliation 2 into Bhim Gopal Dhoubhadel's affiliations: Bhim Gopal Dhoubhadel 1, 2. In addition, the full address of the affiliation 2 is changed as below.

Institute of Tropical Medicine, Nagasaki University, 1-12-4 Sakamoto, Nagasaki, 852-8523, Japan

\section{Author details}

${ }^{1}$ School of Tropical Medicine and Global Health (TMGH), Nagasaki University, 1-12-4 Sakamoto, Nagasaki 852-8523, Japan. ${ }^{2}$ Institute of Tropical Medicine, Nagasaki University, 1-12-4 Sakamoto, Nagasaki 852-8523, Japan. ${ }^{3}$ Siddhi Memorial Hospital, Bhaktapur, Nepal. ${ }^{4}$ Present address: Michio Yasunami, Life Science Institute, Saga-Ken Medical Centre Koselkan, Saga, Japan. ${ }^{5}$ Graduate School of Biomedical Sciences, Nagasaki University, Nagasaki, Japan. ${ }^{6}$ Clinical Sciences, Liverpool School of Tropical Medicine, Liverpool, UK. ${ }^{7}$ Institute of Infection and Global Health, University of Liverpool, Liverpool, UK.

Published online: 22 September 2020

\section{Reference}

1. Dhoubhadel, et al. Trop Med Health. 2020;48:53.

\footnotetext{
The original article can be found online at https://doi.org/10.1186/s41182020-00225-8

* Correspondence: b-gopal@nagasaki-u.ac.jp

${ }^{\dagger}$ Bhim Gopal Dhoubhadel and Ganendra Bhakta Raya contributed equally to this work.

'School of Tropical Medicine and Global Health (TMGH), Nagasaki University,

1-12-4 Sakamoto, Nagasaki 852-8523, Japan

${ }^{2}$ Institute of Tropical Medicine, Nagasaki University, 1-12-4 Sakamoto,

Nagasaki 852-8523, Japan

Full list of author information is available at the end of the article
}

(c) The Author(s). 2020 Open Access This article is licensed under a Creative Commons Attribution 4.0 International License, which permits use, sharing, adaptation, distribution and reproduction in any medium or format, as long as you give appropriate credit to the original author(s) and the source, provide a link to the Creative Commons licence, and indicate if changes were made. The images or other third party material in this article are included in the article's Creative Commons licence, unless indicated otherwise in a credit line to the material. If material is not included in the article's Creative Commons licence and your intended use is not permitted by statutory regulation or exceeds the permitted use, you will need to obtain permission directly from the copyright holder. To view a copy of this licence, visit http://creativecommons.org/licenses/by/4.0/. 